\title{
Research priorities for public health sciences in the postgenomic era
}

Public interest in human genome research hinges on its promise for improving human health, perhaps the ultimate ambition of the Human Genome Project. ${ }^{1}$

Sequencing the genome ahead of schedule has raised expectations that health benefits will follow quickly. However, new gene discoveries have thus far had little impact on preventive medicine, giving rise to some skepticism about the ultimate value of genomic information for preventing common diseases. $^{2}$

How will research findings in genomics be translated into information for preventing disease and improving health? In his commentary, Omenn ${ }^{3}$ makes a strong case for public health sciences as part of the answer. This assertion at first seems incongruous with the popular notion of genetics as the key to individualized medicine. However, as Omenn notes, human genetics and public health sciences share certain essential perspectives: a focus on populations, interest in variation, and recognition of the importance of social context. Genetics bridges clinical medicine and public health by extending counseling and treatment beyond the individual to families. Epidemiologic studies generate hypotheses and test them in clinical trials before intervention is recommended to individual patients. In the end, public health sciences are the tools for understanding gene-environment interactions at the core of nearly all human diseases. In addition to epidemiology and biostatistics, these tools include specialized methods for studying health effects of the physical and chemical environment ("ecogenetics"), the microbial milieu ("pathobiology"), human behavior, and the organization of health services.

Where should the public health sciences focus first to begin translating genomic research findings into health information? We propose three priority research areas that clearly call for a public health approach:

- Understanding genomic factors in health of populations.

- Examining the value of genomic tests for screening and prevention.

- Assessing family history as a tool for prevention.

Because the success of this research agenda depends on broad participation by an informed community, we also advocate further investment in better ways to communicate about genetics.

\section{Understanding genomic factors in the health of populations}

The basic science of public health genomics is "human genome epidemiology," the set of methods for collecting, analyzing, and synthesizing population-based data on the distribution of gene variants, gene-disease associations, and gene- environment and gene-gene interactions. ${ }^{4}$ Epidemiologic studies are needed to estimate the absolute, relative, and attributable risks required to gauge the effects of genomic factors in the health of individuals and populations. To yield meaningful inferences, these studies must be conducted systematically in populations defined by geopolitical boundaries, rather than limited to the more genetically homogeneous families or groups in which susceptibility genes are usually first identified. For example, BRCA1 mutations were first associated with breast cancer in epidemiologic studies of large, multicase families; however, because of other shared, unmeasured genetic and environmental factors, the absolute risk of breast cancer is higher in these families than in families with only one affected member or none at all. ${ }^{5}$ Generalizing risk estimates from multicase family studies to the entire population of women with BRCA1 mutations would be misleading and could cause harm, subjecting women to excessive anxiety and unnecessary treatment.

Most cases of breast cancer and other common chronic diseases are thought to arise from interactions among multiple genes, environmental exposures, and behaviors over a long period of time. Although a person's genetic sequence is determined at conception, gene expression varies continuously among tissues, in response to environmental stimuli and with age, reflecting cumulative effects over the course of a lifetime. The interactions of gene products with each other and with other factors in their milieu reflect an underlying complex "genetic architecture." 6 While technical advances continue to increase the capacity of epidemiologic studies to carry out largescale genotyping and measurement of biomarkers, the ability to assimilate, synthesize, and interpret the data has not yet fully caught up. New methods are needed if these data are to be translated into useful information for predicting disease and guiding interventions.

A special challenge for public health is the integration of genomics into the public health response to cancer clusters, outbreaks of infectious diseases, acute effects of toxic exposures, or adverse events following vaccination. The capacity to measure genetic variation, gene expression, and biomarkers will enhance the acuity of public health investigations. For example, variation in the paraoxonase (PON1) gene has been associated with acute and long-term health effects of exposure to certain organophosphate pesticides widely used in agriculture. Recognizing this variation in susceptibility can help define the health impact of pesticide exposure and inform policies to protect the safety and rights of farm workers. ${ }^{7}$ 


\section{Examining the value of genomic tests for screening and prevention}

Extensive media coverage of genomic discoveries has fueled the public appetite for personalized medicine and a rush to develop and market new genomic tests, ${ }^{8}$ often without the necessary intervening research. Public health sciences have an important role in evaluating the validity and utility of genomic tests, which include not only DNA-based tests for single gene variants, but complex genotypes, tests for acquired mutations, and measures of gene expression, from RNA microarrays to biochemical assays. Before a genomic test can be used for epidemiologic research or clinical practice, laboratory comparison with a gold standard must demonstrate analytic validity. Epidemiologic studies are needed to establish clinical validity (sensitivity, specificity, and predictive value). Many different disciplines, including behavioral and social sciences, will contribute to assessing a test's clinical utility-the sum total of benefits and risks accruing from testing and the ultimate measure of a genomic test's added value.

Public health policies backed by research are necessary to balance the intense commercial interest in genomic screening tests as a new opportunity for direct marketing to individuals. ${ }^{910}$ Health services research will provide important information on the availability, determinants, extent, and patterns of use of genomic tests. Policies regarding genomic testing require ongoing evaluation in the evolving social context of ethical principles, legal requirements, and social concerns. In particular, principles of population screening - the traditional domain of public health - will require rethinking in the age of genomic medicine. ${ }^{11}$

\section{Assessing family history as a tool for prevention}

Until recently, research on genetic factors in disease has been limited almost exclusively to analysis of single, highly penetrant gene variants (e.g., $B R C A 1$ ), which because of their rarity account for only a small proportion of cases of common diseases. The remainder likely result from complex gene-environment interactions that remain poorly understood. Although methods for studying these interactions are still at an early stage of development, family history provides another potential measure of shared genetic risk, as well as the influences of common diet, behaviors, and other nongenetic factors.

A public health research agenda for evaluating family history as a source of "genomic" data for prevention requires an instrument that is relatively simple, can be used in combination with other risk factors to stratify risk (high, moderate, or average), and is useful for directing interventions. ${ }^{12}$ For example, individuals or families at high risk could be offered a genetic evaluation (perhaps including genetic testing), while those at moderate risk are targeted for more intensive screening or lifestyle interventions. An interdisciplinary, public health research effort—including behavioral and social sciences—is required to evaluate family history as a tool for effecting positive changes in health behaviors and improved health outcomes.

\section{Communicating about genetics}

Ultimately, the potential of genomic research for improving health hinges on broad public participation in research. Public health scientists are well situated to help engage communities in setting the research agenda and balancing individual and social concerns, such as privacy and information sharing. A public health perspective can enhance the ongoing dialog about informed consent and confidentiality and can enhance the communication of research results to individuals, families, and communities. ${ }^{13}$

Public health scientists can help keep the "public" connected with the "science" by promoting meaningful communication about genomics among research organizations, professional groups, public health agencies, and the public. ${ }^{14}$ These efforts will encourage collaboration and help bridge individual and community perspectives, enhancing the potential return on public investment in genomic research.

Marta Gwinn, MD, MPH
Muin J. Khoury, MD, PhD
Office of Genomics and Disease Prevention
National Center for Environmental Health
Centers for Disease Control and Prevention
Atlanta, Georgia

\section{References}

1. Collins FS, Patrinos A, Jordan E, Chakravarti A, Gesteland R, Walters L. New goals for the US Human Genome Project: 1998-2003. Science 1998;282:682-689.

2. Holtzman NA, Marteau TM. Will genetics revolutionize medicine? N Engl J Med 2000;343:141-144.

3. Omenn G. The crucial role of the public health sciences in the postgenomic era. Genet Med 2002;4(suppl):21S-26S.

4. Khoury MJ. Human genome epidemiology: translating advances in human genetics into population-based data for medicine and public health. Genet Med 1999;1:7173.

5. Begg CB. On the use of familial aggregation in population-based case probands for calculating penetrance. J Natl Cancer Inst 2002;94:1221-1226.

6. Sing CF, Haviland MB, Reilly SL. Genetic architecture of common multifactorial diseases. Ciba Found Symp 1996;197:211-229.

7. Battuello K, Fenske R, Furlong C, Austin M, Burke W. Genetic variation in PON1 and pesticide sensitivity (March 13, 2002). http://depts.washington.edu/ceeh/issues/PON.pdf (accessed August 26, 2002).

8. Sciona. Discover the relationship between you and your genes. http://www.sciona.com/ (accessed August 26, 2002).

9. Hull SC, Prasad K. Reading between the lines: direct-to-consumer advertising of genetic testing in the USA. Hastings Cent Rep 2001;31:33-35.

10. Agovino T. Myriad to market genetic testing. Salt Lake Tribune. http://www.sltrib.com/2002/jun/06062002/business/743155.htm (accessed August 26, 2002).

11. Khoury MJ, McCabe LL, McCabe ERB. Population screening in the age of genomic medicine. $\mathrm{N}$ Engl J Med. In press.

12. Yoon P, Scheuner MT, Khoury MJ. Research priorities for evaluating family history in the prevention of common chronic diseases. Am J Prev Med. In press.

13. Beskow LM, Burke W, Merz JF, Barr PA, Terry S, Penchaszadeh VB, Gostin LO, Gwinn M, Khoury MJ. Informed consent for population-based research involving genetics. JAMA 2001;286:2315-2321.

14. Khoury MJ, Thrasher JF, Burke W, Gettig EA, Fridinger F, Jackson R. Challenges in communicating genetics: a public health approach. Genet Med 2000;2:198-202. 